\title{
Can service firms overdo service recovery? An assessment of non-linearity in service recovery satisfaction
}

\author{
C. Boshoff* \\ Department of Business Management, University of Stellenbosch, \\ Private Bag X1, Stellenbosch 7600, Republic of South Africa \\ cboshoff@sun.ac.za
}

Received March 2012

\begin{abstract}
Owing to the human nature of service delivery service failures occasionally occur. Persistently poor service delivery will, however, have a harmful impact on the survival and growth prospects of service firms. Service failure thus calls for remedial action, better known as service recovery. A variety of remedies have been proposed over the years. These remedies or tactics include fixing the problem, apologising, compensation (financial compensation or other forms of redress), a timely response and offering an explanation. A general theme in the service recovery literature is that 'more is better'. The validity of this contention has, however, not been adequately considered. In other words, in a service recovery context, is more always better? Can service recovery be over-done (known as 'over-benefitting')? If so, what are the consequences? Based on the results of two field-type experimental studies involving a sample of 12800 respondents the conclusion is that over-benefitting can be counter-productive. Over-benefitting consistently produced satisfaction scores lower than service recovery that was more moderate in nature.
\end{abstract}

*To whom all correspondence should be addressed.

\section{Introduction}

Service recovery has consistently been identified as one of the most under-researched areas of services marketing (Brown, Fisk \& Bitner, 1994). Webster and Sundaram (1998: 153) lamented: "Our limited knowledge regarding service failure recovery is unfortunate". As recently as 2007, in reviewing the research focus areas of importance in services research in the foreseeable future, Grewal and Levy (2007) identify 'Understanding the components of service recovery and their main and interactive effects on patronage' as one of the key areas in need of further scrutiny.

One common theme in the service management literature is that once service failure occurs, a firm should initiate some attempt to recover the situation to avoid the negative impact of word-of-mouth, loss of sales and market share loss. A variety of remedies have been proposed over the years. These include fixing the problem, apologising, providing compensation (financial compensation or other forms of redress), a timely response and offering an explanation (Boshoff, 1997). Over time a series of mostly experimentaltype studies investigated the levels at which these remedies ought to be offered to aggrieved customers (see Grewal, Roggeveen and Tsiros 2008 for a summary). A general theme in the literature is that 'more is better'. In other words, service staff are encouraged to do 'whatever it takes' to fix the problem. The validity of this type of approach to service recovery has not been critically considered.

Although the issue of 'customer delight' has been studied in a service marketing context (Finn, 2005), few researchers have investigated the impact of excessive levels of service recovery and its potential outcomes. Estelami and De Maeyer (2002), a rare exception of the latter, investigated delighting (exceeding customers' expectations) service recovery experiences in different service industries, using a content analysis approach. They attempted to identify the sources of customer delight (exceeding customers' expectations) in service recovery. It was concluded that compensatory-related service recovery actions (a free service or a discount) dominated 'delightful' service recoveries.

However, no attempt has been made to investigate the impact of increasingly higher levels or excessive levels of service recovery on outcome variables such as customer satisfaction or satisfaction with service recovery. Related questions are: Is there a linear relationship between service recovery and customers satisfaction with the service recovery offered. In other words, can service recovery be overdone? More importantly, can service recovery be overdone to such an extent that its intended desirable outcomes (returning a customer to a state of satisfaction, reestablishing loyalty) can be negatively influenced? More specifically, can the benefits of service recovery increase up to a point and then decline, leading to wastage of a service firm's resources?

Against this background the objective this study was to assess whether the relationship between the level of service recovery (amount of apologising offered by the offending service provider and the amount of compensation offered) and satisfaction with service recovery is linear or non-linear. 


\section{Service recovery}

"Service recovery" refers to the actions by a service firm to restore a customer to a state of satisfaction after a service failure and complaint. In other words, service recovery offers the firm a second opportunity to meet a service customer's expectations and is primarily aimed at ensuring the complaining customer's loyalty (DeWitt, Nguyen \& Marshall, 2008). Service recovery is of particular importance to service firms (Luria, Gal \& Yagil, 2009). Poor or ineffective service recovery leads to undesirable outcomes such as customer complaints, defections to competing firms and negative word-of-mouth. Effective service recovery (satisfaction with service recovery), on the other hand, avoids these negative outcomes and may even enhance customer satisfaction and loyalty to higher than pre-service failure levels (Priluck \& Lala, 2009).

Much of contemporary research on service recovery and understanding how service recovery actions are perceived by customers has focused on justice and equity theory as theoretical foundation.

\section{Service recovery, justice theory and equity theory}

Poor service delivery is by definition an inequitable situation. A consumer has paid for a service which did not meet his or her expectations. Justice theory would predict that in such a situation an aggrieved consumer would try to restore equity by complaining to the service provider and expecting some form of remedial action. The evaluation of this remedial action may be considered on three dimensions: procedural justice, interactional justice and distributive justice (Sparks \& McColl-Kennedy, 2001; Schoefer, \& Diamantopolous, 2008; Gustafson, 2009).

Distributive justice implies an assessment of inputs and outcomes. In service terms it means that if service recovery is offered by the service firm the customer would then evaluate his input/output ratio and then decide whether the service firm's complaint handling action is fair or not (Sheppard, Lewicki \& Minton, 1992). This assessment, against the background of distributive justice, is particularly important in transaction-specific satisfaction but is often moderated by considerations such as the type of the complaint (Gelbrich \& Roschk, 2011).

Based on the work of Adams (1963), a distinction has been made between negative inequity (under-benefitting), equity and positive inequity (over-benefitting). A situation that is seen as equitable by both parties in this exchange is the most desirable (Adams, 1965), and should not have further consequences. However, both negative inequity (underbenefitting) and positive inequity (over-benefitting) will lead to some form of distress. It is fairly well documented that in the case of under-benefitting the consumer may 'use' the distress or tension as a source of motivation for behaviours such as negative word-of-mouth and disloyalty. Less well documented is how consumers deal with the tension that emanate from positive inequity or overbenefitting. According to Anderson, Berger, Zeldich and Cohen (1969) over-benefitting also creates tension - possibly due to feelings of guilt and embarrassment - that consumers will also try to reduce or eliminate.

Over-benefitting will, however, not be perceived the same by all beneficiaries. Huseman, Hatfield and Miles (1987) distinguish between three groups of individuals and suggest that there are Benevolents (or 'givers' who dislike to be at the receiving end of social exchanges), Entitleds (or 'getters' who want what they get to be more than what they put in) and the Equity Sensitives (those who want what they received to be in line with what they put in). The Equity Sensitives are likely to be disturbed by both underbenefitting and over-benefitting.

\section{Over-benefitting in service recovery}

The potential benefits for a business firm of exceeding customer expectations or delighting the customer have been investigated in the marketing literature (Estelami \& De Maeyer, 2002; Rust \& Oliver, 2000; Finn, 2005). In a service recovery context offering a dissatisfied customer more than what could be expected after a service failure has been described as both 'service provider generosity' (Estelami \& De Maeyer, 2002) and 'over-benefitting' (Gilly \& Hansen, 1985). In broad terms it can be described as giving aggrieved customers value beyond their expectations.

Despite possible intuitive expectations to the contrary, Garrett (1999) found that complaining customers are not always more 'impressed' with greater amounts of coupon compensation in response to complaints. In similar vein, some researchers have cautioned that 'over-benefitting' may even lead to negative outcomes. Estelami and De Maeyer (2002), for instance, did a content analysis of responses to open-ended questions related to service recovery situations and concluded that as generosity increased, the 'thought polarity index' (a positive TPI-score indicates that positive comments exceed negative comments) actually decreased. In similar vein, McQuilken (2008: 11) found that perceived employee effort was not evaluated more positively when higher compensation was forthcoming.

An explanation offered for these counter-intuitive results is that over-generosity/over-benefitting (or excessively generous service recovery-related pay-outs) impacts negatively on perceptions of justice (McQuilken, 2008: 11), and may lead to suspicion among customers (Estelami \& De Maeyer, 2002: 207). Another explanation for the contention that over-benefitting has negative outcomes is that it may be seen as inequitable (Sparks \& McColl-Kennedy, 2001) and customers feeling uncomfortable (Zeithaml, Bitner \& Gremler, 2006: 225) or experiencing feelings of guilt and indebtedness towards the service provider (McCollough, Berry \& Yadav, 2000).

Other researchers, however, reported results that contradicted these findings. Hocutt and Bowers (2005: 16), for instance, reported that, in a hotel environment, both high and moderate levels of redress lead to significantly enhanced customer satisfaction compared to low levels of redress. Negative word-of-mouth (WOM) intentions were also significantly lower when high levels of redress were offered by the hotel (Hocutt \& Bowers, 2005: 17). 
These finding are in line with results reported by Boshoff (1997), Gilly and Hansen (1985) and Maxham III (2001). Boshoff's (1997) results showed that those who experienced financial gain (over-benefitting) were significantly more satisfied with the service firm's service recovery effort than those who were simply compensated for their loss (described by some as equity). Gilly and Hansen (1985) reported that over-benefitting had a positive impact on satisfaction, repurchase intentions and positive word-ofmouth. In similar vein, Maxham III (2001) found that high and medium levels of compensation lead to relatively higher levels of customer satisfaction than low compensation. Megehee (1994: 214) found that larger monetary amounts of 'restitution' were positively related to several outcome variables including satisfaction and intention to purchase.

One explanation for these conflicting findings is the inconsistent use of what is regarded as over-benefitting. These inconsistencies lead McQuilken (2009: 92) to conclude that "... the question of whether compensation should go beyond this level [complainers must at least be returned to their starting point before the service failure occurred] remains unanswered" and calls for "... further research into compensation".

This overview shows that, although the relationship between over-benefitting and organisational outcomes such equity perceptions, customer satisfaction and loyalty have been investigated to some extent, the empirical results have been inconsistent. More importantly, the question whether 'higher' levels of service recovery will necessarily produce 'higher' levels of the desirable outcomes expected (such as customer satisfaction) or whether the returns on the 'investment' in service recovery may actually diminish (that is non-linear) has not been investigated.

\section{Homans' law and the law of diminishing returns}

The issue of over-benefitting in service recovery can be viewed from both a consumer perspective and a managerial perspective. Homans (1974) deprivation-satiation proposition suggests that the more often a person is rewarded the less valuable any further unit of this reward will become. In a service recovery context the proposition proposes that a complaining customer's satisfaction with ever-increasing levels of service recovery (such as compensation) will diminish over time as it becomes less and less 'valuable'. Homans' proposition (the customer perspective) is consistent with the law of diminishing returns.

The law of diminishing returns (the managerial perspective) is a classic economic concept that suggests that as more 'investment' in an area is made, overall return on that investment increases at a declining rate, assuming that all variables remain fixed. To continue to make an investment after a certain point will lead to decreasing returns on that input. From a consumption perspective it means that as a person increases consumption of a product or service - while keeping consumption of other products constant - there is a decline in the marginal utility that that person derives from consuming each additional unit of that product (Parkin,
2010: 182-183). From a managerial perspective, continued investment is thus a waste of resources.

The law of diminishing returns has broader applications than economics. In fact, it is one of the most widely recognised economic principles outside the domain of economics. It is a concept that often influences managerial decision-making. A marketing manager, for instance, may have to consider how many times to flight an advertisement of a new product of brand on television, for instance. At what point will consumer awareness be sufficient that additional advertising will no longer justify the cost of flighting the advertisement? Service managers trying to enhance the quality of service of a call centre will reach a point where adding new agents to the team will not add to the quality of the service offered to customers. In other words, at what point does the additional 'investment' of resources result in diminishing returns (in service marketing terms it can be declining service quality or declining customer satisfaction)?

This study investigates whether the law of diminishing returns also apply in the domain of service recovery by considering whether continuously increasing the level of 'investment' in service recovery will yield diminishing returns.

Both the law of diminishing returns and earlier research on the relationship between over-benefitting and organisational outcomes such as equity perceptions and customer satisfaction suggest that the relationship between the extent of service recovery and the resultant customer satisfaction could be non-linear. This relationship has, however, not been empirically investigated.

\section{Problem statement}

In the marketing strategy literature the word 'overkill' often surfaces. It implies that too much of a good thing can lead to negative outcomes. In the context of service failure and service recovery the question can be raised: can service firms overdo service recovery?

In other words, can service recovery be overdone to such an extent that its intended desirable outcomes (returning a customer to a state of satisfaction, re-establishing loyalty) can be negatively influenced? More specifically, can the satisfaction with service recovery increase up to a point and then decline?

\section{The dependent and independent variables}

The dependent variable in this study was 'satisfaction with service recovery' (SSR). The independent variables are the two service recovery remedies namely 'apologising' and 'compensation. Both 'apologising' and 'compensation' were measured at four levels: low/none, moderate, high and excessive. 


\section{Objectives}

Much of the research conducted in both marketing and service marketing investigate linear relationships between variables using statistical tests such as correlation analysis, regression analysis and even structural equation modelling. In services marketing Finn's (2012) study is one of the few that investigated a non-linear relationship - that between customer satisfaction and customer delight. Finn's (2012) study was concerned with the question whether managers should invest in customer delight once they have reached a satisfactory level of customer satisfaction. However, Finn's study did not investigate satisfaction with service recovery.

Against this background, the objective of this study was to assess whether the relationship between the level of service recovery (amount of apologising offered by the offending service provider and the amount of compensation offered and satisfaction with service recovery), is linear or nonlinear.

This "goldilocks"-type study (not too much, not too little, just right) is common in psychology studies and the inverted $\mathrm{U}$ is well known for many manipulations (Goodrich, Kirby, Oros, Wagstaff, McDevitt, Hazan \& Peters, 2004; Goldenhar, Hecker, Moir \& Rosecrance, 2003). In this study it is hypothesised that there is a non-linear relationship between the independent variables, namely amount of service recovery (compensation and apologising) and the dependent variable 'satisfaction with service recovery'.

\section{Methodology}

\section{Research design}

To address the primary objective a scenario-based, field experiment was designed. All respondents were exposed to a hypothetical service failure situation scenario (see Appendix A for an example) and asked to pretend that the service failure happened to them. They were then asked how satisfied they would be if such a service failure happened to them and if the offending service firm responded in the manner described. Study 1 asked the respondent about a hypothetical service failure scenario at a dry cleaner and the validation study (Study 2) about a restaurant scenario.

The scenario-based method of data collection used in this study closely resembles similar studies by Bitner (1990), McCollough et al. (2000), Hocutt and Bowers (2005) and Dalimore, Sparks and Butcher (2007). Scenario-based data collection yields advantages and disadvantages. Besides considerable control over otherwise uncontrollable variables and favourable cost implications, the researcher is afforded the opportunity to compress the time of "real life" events into more manageable units (Bitner 1990: 75). Bitner (1990) points out that the method permits control over the manipulation of variables such as time but accepts that it compromises external validity to some extent due to the assumption that participants' responses will reflect their actual behaviour. As she correctly points out, however, this 'loss' is counteracted by realistic scenarios which should enhance external validity. The methodology also avoids the problems associated with recall and memory loss, the potential impact of demand effects, as well the potential problems with ethical concerns related to service failures that never occurred.

All respondents were randomly assigned to one the 32 different scenarios (16 dry-cleaning scenarios and 16 restaurant scenarios) as recommended by Zikmund, Babin, Carr and Griffin (2010) and others, by randomising the names on the data base.

\section{Sampling}

The data were collected by means of an online survey. The size of the data base used was 12800 individuals (half of them participated in Study 1, dry-cleaning; and the other half in Study 2, restaurants). In total 2009 people responded - an effective response rate of $15.7 \%$. Exactly 400 potential respondents each received one of the questionnaires. The response rate per scenario for the 32 scenarios ranged from $12 \%$ to $19 \%$ (the lowest number of respondents for a scenario was 48 and the largest number of observations for a scenario 76).

The service industries chosen were selected because of their common, general use and because they have been studied previously in service recovery research - dry cleaning (Webster \& Sundaram, 1998) and restaurants (De Ruyter \& Wetzels, 2000; Estelami \& De Maeyer, 2002).

\section{Measurement}

The measurement of the levels of compensation were: Excessive compensation (a 150\% refund, scored as level 4), High compensation (a 100\% refund, scored as level 3), Moderate compensation (a 50\% refund, scored as level 2) and No compensation ( $0 \%$ refund, scored as level 1$)$. The measurement of the levels of apologising was: Excessive apologising (six times, scored as level 4), High apologising (four times, scored as level 3), Moderate apologising (twice, scored as level 2) and No apologising (no apology, scored as level 1). This study was thus a 4 X 4 between-subject, full factorial design.

The resultant sixteen scenarios are shown in Table 1.

After the respondents had read the selected scenarios, they were asked to pretend they were the customer in the scenario who experienced the service failure and then to complete a questionnaire to measure their perceived satisfaction with the dry cleaner's (restaurant in the case of the validation study) service recovery efforts. In other words, the dependent variable in this study was satisfaction with service recovery measured on a four-point satisfaction scale adapted from Voss, Parasuraman and Grewal (1998). 
Table 1: Scenario descriptions

\begin{tabular}{c|c}
\hline Scenario 1: & Excessive compensation, excessive apologising \\
\hline Scenario 2: & Excessive compensation, high apologising \\
\hline Scenario 3: & Excessive compensation, moderate apologising \\
\hline Scenario 4: & Excessive compensation, no apologising \\
\hline Scenario 5: & High compensation, excessive apologising \\
\hline Scenario 6: & High compensation, high apologizing \\
\hline Scenario 7: & High compensation, moderate apologizing \\
\hline Scenario 8: & High compensation, no apologizing \\
\hline Scenario 9: & Moderate compensation, excessive apologizing \\
\hline Scenario 10: & Moderate compensation, high apologising \\
\hline Scenario 11: & Moderate compensation, moderate apologising \\
\hline Scenario 12: & Moderate compensation, no apologising \\
\hline Scenario 13: & No compensation, excessive apologising \\
\hline Scenario 14: & No compensation, high apologising \\
\hline Scenario 15: & No compensation, moderate apologising \\
\hline Scenario 16: & No compensation, no apologising \\
\hline
\end{tabular}

\section{Pre-test}

To assess whether the manipulations used in this study measure what they were supposed to measure, a pre-test was conducted. A small sample of 100 individuals from the same population was asked to rate four different scenarios (each scenario was rated by at least twenty individuals). Four scenarios were selected, measuring all four levels of compensation and apologising, namely Scenario 1 (excessive compensation, excessive apologising), Scenario 6 (high compensation, high apologising), Scenario 11 (moderate compensation, moderate apologising) and Scenario 16 (no compensation, no apologising).

Each individual respondent was presented with a scenario (see Appendix A) and asked to indicate whether they would regard the compensation offered as excessive/high/ moderate/none on a 4-point scale labelled as excessive (4), high (3), moderate (2) and none (1). They would use the same scenario to rate the level of apologising as: excessive (4), high (3), moderate (2) and none (1). The means score per scenario are shown in Tables 2 - 5 .

A one-sample t-test was then conducted to assess whether each level's mean was statistically different from the next level. Tables 2 to 5 show that for both Study 1 and Study 2 all means are statistically different from the next level and in the expected direction. Based on these results it was concluded that the manipulations were effective.

\section{Empirical results}

\section{Demographic profile}

The unit of analysis surveyed in this study was adults of both genders older than 18 years of age. Of the 6400 consumers surveyed in Study 1 (dry-cleaning) 972 responded - an effective response rate of $14.2 \%$. Of these $70,1 \%$ were male and $29,9 \%$ were female. The age distribution was: $13,0 \%$ between 21 and 30 years of age, $35,4 \%$ between 31 and 40 years of age, 33,7\% between 41 and 50 years of age and $18,8 \%$ fifty years of age or older.
In Study 2 (restaurants), 1037 out of 6400 people responded - a response rate of $16.2 \%$. The gender distribution in Study 2 (restaurants) was $68.4 \%$ were male and $31.6 \%$ were female. The age distribution was: $11.2 \%$ between 21 and 30 years of age, $35.8 \%$ between 31 and 40 years of age, $33.2 \%$ between 41 and 50 years of age and $19.9 \%$ fifty years of age or older. In both studies there was thus a slight gender bias (more males) but the age distribution followed what appears to be a normal distribution.

\section{Satisfaction scores}

All respondents were presented with the following service failure scenario (in the case of dry-cleaning): You drop off $a$ week's clothing at your neighbourhood dry-cleaner every Friday morning to be picked up the next day. On this occasion, when arriving at the dry cleaner on the Saturday afternoon you are informed by the manageress that there has been a misunderstanding and that your clothing will only be ready on Tuesday.

This service failure scenario was then followed by a service recovery scenario. Each of the 16 scenarios had a unique service recovery response (see Appendix A for an example) from the service provider (manipulating both compensation and apologising at four levels) and each respondent could subsequently rate their post-service recovery satisfaction on a four-point satisfaction scale.

\section{Reliability results}

The reliability results (Cronbach alpha) of the satisfaction with service recovery scores are shown in Table 6. In the majority of cases (for both Study 1 and Study 2) the values exceed the customary cut-off of 0,7 (Nunnally \& Bernstein 1994). In the six instances (out of 32) when the Cronbach Alpha is below 0,7 it comfortably exceeds 0,6 which seems to suggest that the scale used was reasonably reliable in measuring satisfaction with the service recover effort. 
Table 2: Pre-test results compensation: dry cleaning

\begin{tabular}{l|l|c|c}
\hline \multicolumn{1}{c|}{ Scenario } & \multicolumn{1}{c|}{ Description } & Mean score & \multirow{2}{*}{ Statistical significance } \\
\cline { 1 - 2 } & \multicolumn{1}{c}{} & \\
\hline Scenario 1 & Excessive compensation & 3,55 & $\mathrm{p}<0,000$ \\
\hline Scenario 6 & High compensation & 2,90 & $\mathrm{p}<0,000$ \\
\hline Scenario 11 & Moderate compensation & 2,55 & $\mathrm{p}<0,000$ \\
\hline Scenario 16 & No compensation & 1,10 & \\
\hline
\end{tabular}

Table 3: Pre-test results apologising: dry cleaning

\begin{tabular}{l|l|c|c}
\hline \multicolumn{1}{c|}{ Scenario } & \multicolumn{1}{c|}{ Description } & Mean score & \multirow{2}{*}{ Statistical significance } \\
\hline Scenario 1 & & 3,85 & \\
\hline Scenario 6 & Excessive apologising & 3,15 & \\
\hline Scenario 11 & High apologising & 2,30 & $\mathrm{p}<0,000$ \\
\hline Scenario 16 & Moderate apologising & 1,10 & $\mathrm{p}<0,000$ \\
\hline
\end{tabular}

Table 4: Pre-test results compensation: restaurant

\begin{tabular}{l|l|c|c}
\hline \multicolumn{1}{c|}{ Scenario } & \multicolumn{1}{c|}{ Description } & \multicolumn{1}{c}{ Mean score } \\
\hline Scenario 1 & Excessive compensation & 3,55 & 3,10 \\
\hline Scenario 6 & High apologising & 2,35 & $\mathrm{p}<0,000$ \\
\hline Scenario 11 & $\begin{array}{l}\text { Moderate compensation, } \\
\text { moderate apologising }\end{array}$ & $\mathrm{p}<0,000$ \\
\hline Scenario 16 & $\begin{array}{l}\text { No compensation, no } \\
\text { apologising }\end{array}$ & 1,05 & $\mathrm{p}<0,000$ \\
\hline
\end{tabular}

Table 5: Pre-test results apologising: restaurant

\begin{tabular}{l|l|c|c|}
\hline \multicolumn{1}{c|}{ Scenario } & \multicolumn{1}{c|}{ Description } & \multicolumn{1}{c}{ Mean score } \\
\hline & & & \\
\hline & & 3,70 & \\
\hline Scenario 1 & Excessive apologising & 3,15 & \\
\hline Scenario 6 & High apologising & 2,20 & \\
\hline Scenario 11 & Moderate apologising & $\mathrm{p}<0,000$ & 1,15 \\
\hline Scenario 16 & No apologising & $\mathrm{p}<0,000$ & \\
\hline
\end{tabular}

Table 6 : Reliability of satisfaction scores (Chronbach's alpha)

\begin{tabular}{|c|c|c|c|}
\hline Scenario number & Service recovery scenario description & Satisfaction Study 1 & Satisfaction Study 2 \\
\hline 1 & Excessive compensation, excessive apologising & 0,784 & 0,856 \\
\hline 2 & Excessive compensation, high apologising & 0,793 & 0,757 \\
\hline 3 & Excessive compensation, moderate apologising & 0,703 & 0,781 \\
\hline 4 & Excessive compensation, no apologising & 0,786 & 0,731 \\
\hline 5 & High compensation, excessive apologising & 0,840 & 0,840 \\
\hline 6 & High compensation, high apologising & 0,836 & 0,611 \\
\hline 7 & High compensation, moderate apologising & 0,821 & 0,646 \\
\hline 8 & High compensation, no apologising & 0,712 & 0,646 \\
\hline 9 & Moderate compensation, excessive apologising & 0,828 & 0,679 \\
\hline 10 & Moderate compensation, high apologising & 0,813 & 0,806 \\
\hline 11 & Moderate compensation, moderate apologising & 0,872 & 0,607 \\
\hline 12 & Moderate compensation, no apologising & 0,724 & 0,623 \\
\hline 13 & No compensation, excessive apologising & 0,782 & 0,812 \\
\hline 14 & No compensation, high apologising & 0,810 & 0,717 \\
\hline 15 & No compensation, moderate apologising & 0,727 & 0,866 \\
\hline 16 & No compensation, no apologising & 0,665 & 0,834 \\
\hline
\end{tabular}




\section{Linearity versus non-linearity: Study 1 (Dry- cleaning)}

To address the problem statement concerning non-linearity the following two hypotheses were considered:

$\mathrm{H}^{1}$ : The relationship between the level of service recovery (compensation) and satisfaction with service recovery is non-linear

$\mathrm{H}^{2}$ : The relationship between the level of service recovery (apologising) and satisfaction with service recovery is non-linear

To address Hypotheses 1 and 2, an analysis of variance was conducted with quadratic terms included. The results summarised in Table 7 and Figure 1 suggest that Hypothesis 1 , in respect of compensation, cannot be rejected (F-value 47,54; $\mathrm{p}<0,001)$. In other words, the relationship between satisfaction with service recovery and increasing levels of compensation is not linear. The same conclusion applies to Hypothesis 2 related to apologising (F-value 5,75; $\mathrm{p}<0,05$ ). $\mathrm{H}^{1}$ and $\mathrm{H}^{2}$ can thus not be rejected in respect of the drycleaning sample.

To assess the relative impact of different levels of compensation and apologising on satisfaction with service recovery (SSR) the satisfaction scores at different levels of each independent variable are plotted in Figure 1. Figure 1 shows that the initial, relatively low levels of compensation and apologising lead to considerable improvements in satisfaction with satisfaction with service recovery, but this improvement levels off quickly and then remains fairly constant after that, irrespective of the level of service recovery offered.

Besides graphically confirming that the non-linear relationships between compensation and apologising on the one hand and satisfaction with service recovery on the other hand, the most significant observations that can be gleaned from Figure 1 are the extremes of the two service recovery remedies, namely 'no service recovery' (in this case no compensation) and 'excessive service recovery' (in this case excessive compensation).

\section{No compensation}

Figure 1 shows that no compensation yields by far the lowest level of SSR when a moderate level of compensation is offered, irrespective of the level of apologising offered. It also shows that 'no apology combined with any level of compensation' yields the lowest SSR. However, offering only moderate levels of apologising in association with moderate levels of compensation result in a significant improvement in SSR. However, increasing the level of compensation and apologising beyond moderate levels will not further enhance SSR. In other words, offering moderate levels of service recovery will enhance SSR well above the 'no-compensation - no-apology' scenario, but increasing service recovery beyond that will not boost SSR further.

\section{Excessive compensation}

The excessive service recovery graphs show a consistent deterioration as the level of compensation and apologising increases. In respect of excessive compensation, Figure 1 shows that when high levels of apologising are combined with excessive compensation the level of SSR is significantly lower when compared to moderate apologising. More importantly, when the level of apologising is increased to excessive levels, the level of SSR reduces even further. Thus, as the level of both apologising and compensation increases, the level of SSR constantly declines. These observations confirm that the relationship between the level of service recovery actions (apologising and compensation) and SSR is not linear as both high and excessive levels of both compensation and apologising are counter-productive in terms of the resultant service recovery satisfaction (SSR).

In most cases when excessive levels of apologising are combined with excessive levels of compensation, the level of SSR is lower than at other levels. Thus, it appears as if service recovery can be overdone.

Table 7: ANOVA results: Study 1, dry cleaning

\begin{tabular}{|c|c|c|c|c|c|}
\hline Factor & SS & df & MS & $\mathbf{F}$ & p \\
\hline Compensation (L) & 7131,84 & 1 & 7131,836 & 289,28 & $0,000 * * *$ \\
\hline Compensation (Q) & 1172,06 & 1 & 1172,06 & 47,54 & $0,000 * * *$ \\
\hline Apologising (L) & 700,48 & 1 & 700,48 & 28,41 & $0,000 * * *$ \\
\hline Apologising (Q) & 141,89 & 1 & 141,89 & 5,75 & $0,017 * *$ \\
\hline $1 \mathrm{~L}$ by $2 \mathrm{~L}$ & 732,96 & 1 & 732,96 & 29,73 & $0,000 * * *$ \\
\hline Error & 23814,86 & 966 & 24,65 & & \\
\hline Total SS & 33278,30 & 971 & & & \\
\hline $\begin{array}{l}\mathrm{R}^{2}=28,4 \% \\
*=\mathrm{p}<0,05 \\
* *=\mathrm{p}<0,01 \\
* * *=\mathrm{p}<0,001\end{array}$ & & & & & \\
\hline
\end{tabular}




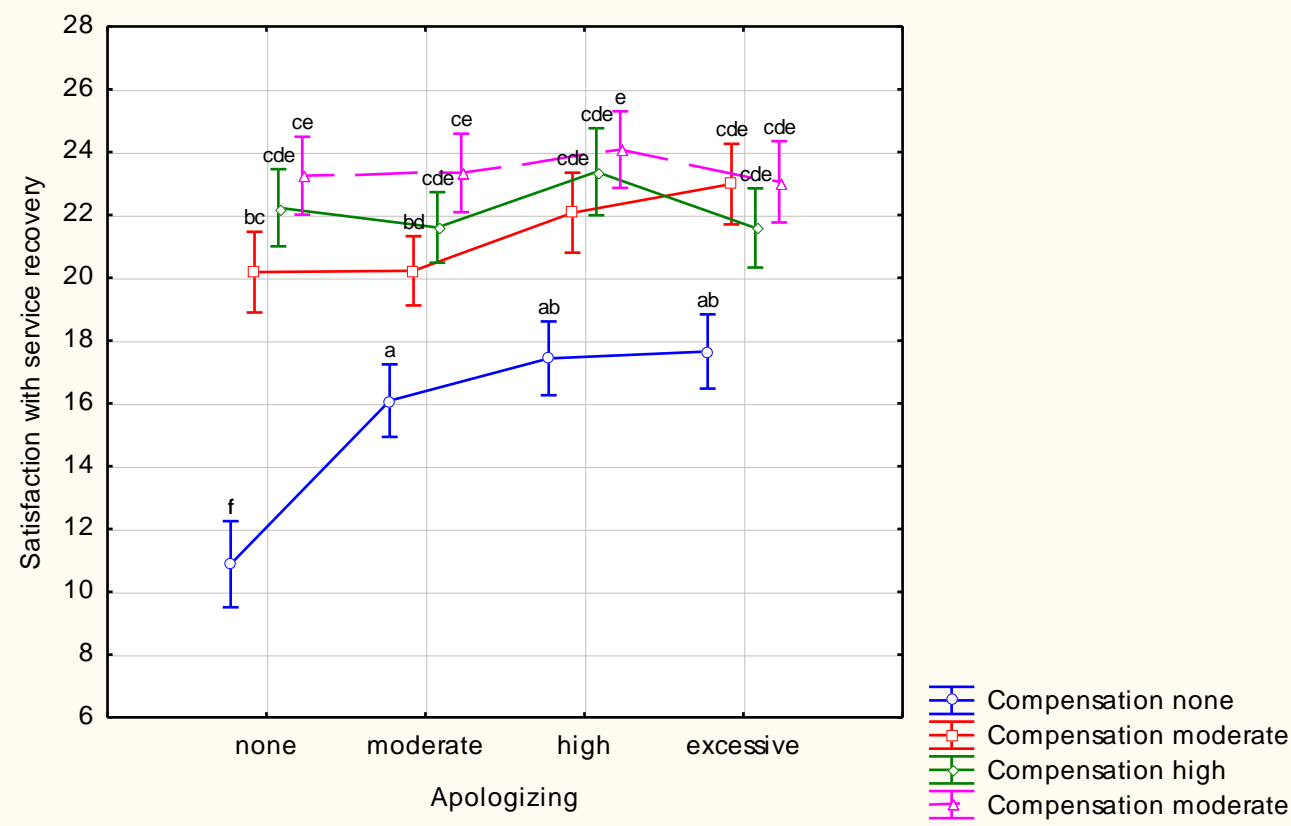

Figure 1: A LS means plot of satisfaction with service recovery at different levels of compensation and apologising: Study 1

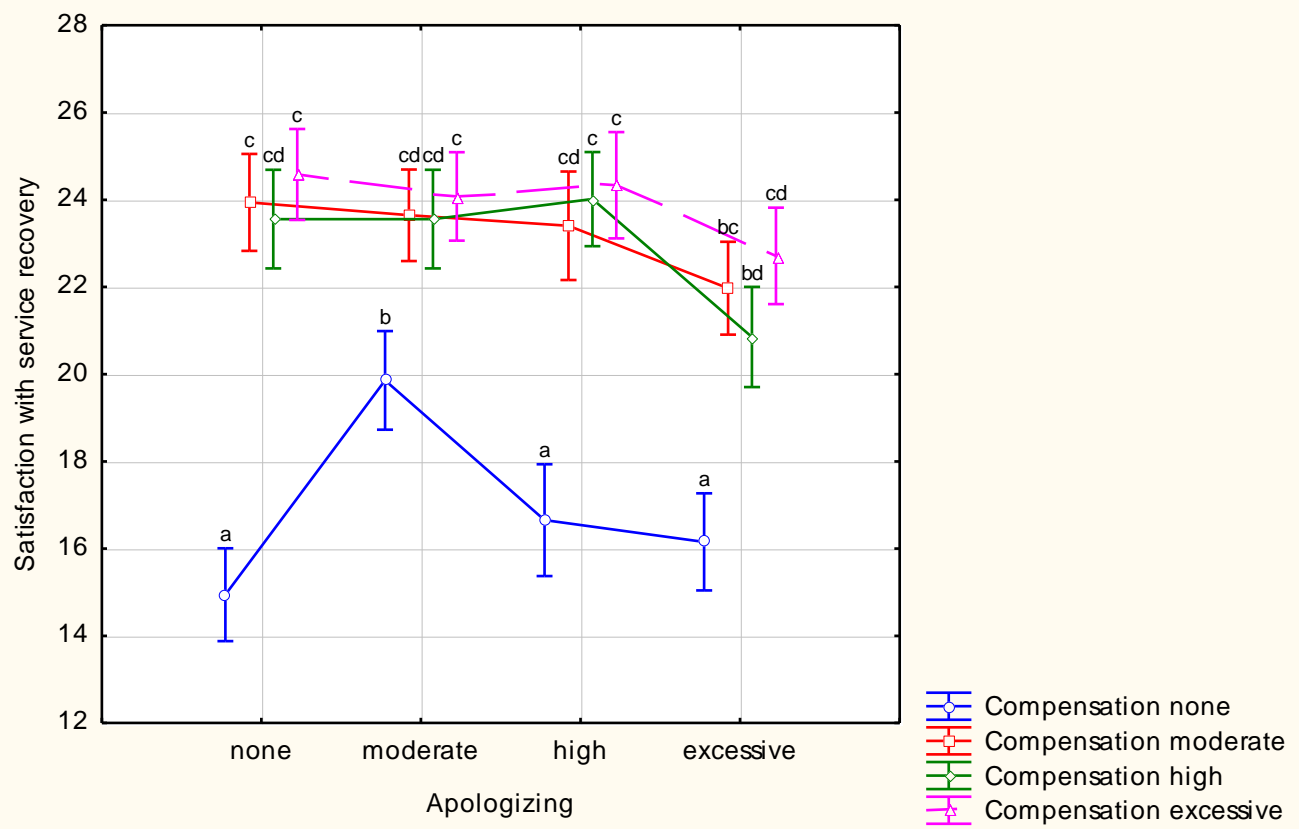

Figure 2: A LS means graph of satisfaction with service recovery at different levels of compensation and apologising: Study 2

\section{Linearity versus non-linearity: Study 2 (Restaurants)}

To validate the results reported in Study 1, the same methodology was used (but not the same sample) to address Hypotheses 1 and 2. In study 2, respondents were asked about a similar scenario in a sit-down restaurant. As was the case in Study 1, an analysis of variance was conducted with quadratic terms included. The results summarised in Table 8 suggest that Hypothesis 1, in respect of compensation cannot be rejected (F-value 86,81; p < 0,001). In other words, the relationship between satisfaction with service recovery and increasing levels of compensation (compensation) is not linear. The same conclusion applies to Hypothesis 2 related to apologising (F-value 20,81; p <
0.001). $\mathrm{H}^{1}$ and $\mathrm{H}^{2}$ can thus not be rejected in respect of the restaurant sample.

The results reported in Table 8 and Figure 2 are consistent with those that emanated from Study 1 .

An inspection of Figure 2 shows that moderate, high and excessive levels of service recovery (in this case a combination of compensation and apologising) produce graphs very similar to Study 1. The 'no compensation' graph differ slightly in the sense that high and excessive levels of service recovery produce SSR scores significantly lower than moderate levels of service recovery. This observation confirms the earlier contention - service 
Table 8: ANOVA results: Study 2, restaurants

\begin{tabular}{|c|c|c|c|c|c|}
\hline Factor & SS & df & MS & $\mathbf{F}$ & p-values \\
\hline Compensation (L) & 5544,63 & 1 & 5544,63 & 250,54 & $0,000 * * *$ \\
\hline Compensation (Q) & 1921,27 & 1 & 1921,27 & 86,81 & $0,000 * * *$ \\
\hline Apologising (L) & 262,58 & 1 & 262,58 & 11,87 & $0,000 * * *$ \\
\hline Apologising (Q) & 460,61 & 1 & 460,61 & 20,81 & $0,000 * * *$ \\
\hline $1 \mathrm{~L}$ by $2 \mathrm{~L}$ & 80,97 & 1 & 80,97 & 3,66 & 0,056 \\
\hline Error & 22816,94 & 1031 & & & \\
\hline Total SS & 31110,13 & 1036 & & & \\
\hline
\end{tabular}

$\mathrm{R}^{2}=26,7 \%$

$* * *=\mathrm{p}<0,001$

recovery can be overdone and can lead to negative consequences such as declining levels of customer satisfaction.

To summarise: the data from both the dry-cleaning and the restaurant sample confirm that there is sufficient support for both $\mathrm{H}^{1}$ and $\mathrm{H}^{2}$. In other words, increasing levels of overbenefitting has a negative in influence of satisfaction with service recovery.

\section{Discussion}

Based on this analysis we can conclude that the option of no service recovery action/remedy (the service doing nothing in response to service failure) consistently yielded the lowest SSR scores and should thus, from a managerial perspective, not be considered. In other words, service firms cannot afford not to have service recovery strategies in place. Failure to respond satisfactorily to service complaints will lead to dissatisfaction and undesirable outcomes such as negative word-of mouth and lost sales. Moderate levels of service recovery yield satisfaction scores that that could be described as 'adequate'. The empirical results in both Study 1 and Study 2 reveal that extending service recovery beyond 'moderate' levels is not beneficial and, more importantly, could even be counter-productive.

The empirical results provide considerable support for justice theory in the sense that over-benefitting consistently produced satisfaction scores lower than service recovery that was more moderate in nature. Justice theory predicts that consumers who receive more than what they are entitled to are likely to experience some form of discomfort and tension. These results point to both managerial implications and implications for theory development.

\section{Managerial implications}

Service failure and the subsequent service recovery both have cost implications - for the aggrieved customer and the offending service firm. A disappointed service customer's costs include the cost of time and effort to register a complaint by calling a call centre or writing a letter of complaint. At more extreme cases it may even be the cost of litigation. Poor service delivery often require that service firms have to employ staff to handle complaints and have to spend money on items such as call centres, grievance procedures and sometimes even adjudication procedures. Extreme cases may end up in courts of law (Shaw 2008).
Failure to anticipate and manage potential and actual service failures can likewise be costly. Loosing sales, loosing loyal customers and losing market share are developments that no firm can endure indefinitely. In short, service failure will have serious cost implications for service firms no matter how one looks at it. From a management perspective, the challenge would thus be to optimise its response to service failures.

The results of this study have shown that a 'no response' option is one that cannot be considered. In judicial terms: justice must not only be done - it must be seen to be done! The costs of inertia are likely to be just too high. The same applies to excessive service recovery or over-benefitting. When a service failure occurs, 'something' has to be done. The results of both studies confirmed, however, that the 'something' does not have to be much. In both studies just moderate levels of service recovery produced optimal levels of satisfaction with service recovery. In both studies moderate compensation meant a $50 \%$ refund. Moderate apologising was apologising twice during the service recovery interaction with an aggrieved customer. In short, effective service recovery should not cost an arm and a leg.

\section{Theoretical implications}

The findings reported here contribute to theory development in two ways. Firstly, the results provide broad support for both the law of diminishing returns and for justice theory. The results of both studies revealed that an escalating 'investment' in service recovery will produce diminishing returns. In other words, as this 'investment' increases (for instance, increasing the extent of service recovery such as compensation offered to an aggrieved customer to ever higher levels) it leads to over-benefitting that do not produce the anticipated beneficial outcomes to the same extent.

Secondly, the results provide some guidelines for the possible refinement of both theories. In its current form neither of the two theories provide theoretical guidelines in terms of incorporating the 'tipping point' when fair service recovery (compensation, apologising) becomes overbenefitting, or when the returns in an investment actually starts diminishing. To consider this refinement may require further research to possibly quantify the 'tipping point' in a variety of different circumstances to allow theorists to use an inductive approach to refine both theories. 


\section{Limitations of the study and future research}

Against the background of the suggested refinement of justice theory and the law of diminishing returns, future research could attempt to empirically quantify the point at which too much of a good thing becomes dysfunctional, especially in service management environments. These proposed studies should incorporate a variety of services including expensive, high involvement services (international travel, for instance) and emergency services (ambulance services, for instance). Such quantification in a diverse range of service industries would benefit efforts to refine our theoretical understanding of consumer behaviour in service failure situations and guide the service recovery efforts to optimise the 'investment' that service managers make in service recovery systems and procedures.

As would be the case with any other experimental study external validity is a cause of potential concern. Despite efforts to ensure that manipulations are interpreted as intended and to ensure that those manipulations are realistic, the results reported here are not based on actual service failures. The respondents were asked to 'role play' - to pretend that they are the aggrieved customer in a hypothetical scenario and then to report how they think they would respond if they find themselves in such a situation. By implication the potential influence of important variables such as emotions (anger for example) are ignored. In addition, neither the service categories (dry cleaning and restaurants) investigated in this study nor the convenience nature of the sampling procedure used, allow for generalisation beyond the present sample. These limitations leave scope for future research.

\section{References}

Adams, J. 1963. 'Toward an understanding of inequity', Journal of Abnormal and Social Psychology, 67(5): 422436.

Adams, J. 1965. Inequity in social exchange: Advances in experimental and social psychology. New York: Academic Press.

Anderson, B., Berger, J., Zelditch, M.J. \& Cohen, B.P. 1969. 'Reactions to inequity', Acta Sciologica, 12(1): 1-12.

Bitner, M. 1990. 'Evaluating service encounters: The effect of physical surroundings and employee responses', Journal of Marketing, 54(2): 69-82.

Boshoff, C. 1997. 'An experimental study of service recovery options', International Journal of Service Industry Management, 8(2): 11-30.

Brown, S.W., Fisk, R.P. \& Bitner, M-J. 1994. 'The development and emergence of services marketing thought', International Journal of Service Industry Management, 5(1): 21-48.

Dallimore, K.S., Sparks, B.A. \& Butcher, K. 2007. 'The influence of angry customer outbursts on service providers' facial displays and affective states', Journal of Service Research, 10(1): 78-92.

De Ruyter, K. \& Wetzels, M. 2000. 'Customer equity considerations in service recovery: A cross-industry perspective', International Journal of Service Industry Management, 11(1): $91-108$.

DeWitt, T., Nguyen, D.T. \& Roger Marshall, R. 2008. 'Exploring customer loyalty following service recovery: The mediating effects of trust and emotions', Journal of Service Research, 10(3): 269-281.

Estelami, H. \& De Maeyer, P. 2002. 'Customer reaction to service provider overgenerosity', Journal of Service Research, 4(3): 205-216.

Finn, A. 2001. 'Mystery shopper benchmarking of durablegoods chains and stores', Journal of Service Research, 3(4): 310-320.

Finn, A. 2005. 'Reassessing the foundations of customer delight', Journal of Service Research, 8(2): 103-116.

Finn, A. 2012. 'Customer delight: Distinct construct or zone of non-linear response to customer satisfaction?' Journal of Service Research, 15(1): 99-110.

Garret, D.E. 1999. 'The effectiveness of compensation given to complaining customers: Is more better?' Journal of Consumer Satisfaction, Dissatisfaction and Complaining Behavior, 12: 26-34.

Gelbrich, K. \& Roschk, H. 2011. 'A Meta-analysis of organizational complaint handling and customer responses', Journal of Service Research, 14(1): 24-43.

Gilly, M.C. \& Hansen, R.W. 1985. 'Consumer complaint handling as a strategic marketing tool', Journal of Consumer Marketing, 4(3): 53-61.

Goldenhar, L.M., Hecker, S., Moir, S. \& Rosecrance, J. 2003. "The "Goldilocks model" of overtime in construction: Not too much, not too little, but just right', Journal of Safety Research, 34: 215-226.

Goodrich, G., Kirby, J., Oros, T., Wagstaff, P., McDevitt, B., Hazan, J. \& Peters, L.J. 2004. 'Goldilocks and the three training models: A comparison of three models of low vision reading training on reading efficiency', Visual Impairment Research, 6(2\&3): 135-152.

Grewal, D. \& Levy, M. 2007. 'Retailing research: Past, present and future', Journal of Retailing, 83(4): 447-464.

Grewal, D., Roggeveen, A.L. \& Tsiros, M. 2008. 'The effect of compensation on repurchase intentions in service recovery', Journal of Retailing, 84(4): 424-434.

Gustafson, A. 2009. 'Customer satisfaction with service recovery', Journal of Business Research, 62: 1220-1223. 
Hocutt, M-A. \& Bowers, M.R. 2005. 'The impact of service guarantees on consumer responses in the hotel industry', Journal of Hospitality and Leisure Marketing, 13(1): 5-23.

Homan, G.C. 1974. Social behavior: Its elementary forms. New York: Harcourt Brace Jovanovich.

Huseman, R. C., Hatfield, J.D. \& Miles, E.W. 1987. 'A new perspective on equity theory: The equity sensitivity construct', Academy of Management Review, 12: 222-234.

Luria, G., Gal, I. \& Yagil, D. 2009. 'Employees willingness to report service complaints', Journal of Service Research, 12(2): 156-174.

Maxham III, G.J. 2001. 'Service recovery's influence on consumer satisfaction, positive word-of-mouth, and purchase intentions', Journal of Business Research, 54(1): 11-24.

McCollough, M.A., Berry, L.L. \& Yadav, M.S. 2000. 'An empirical investigation of customer satisfaction after service failure and recovery', Journal of Service Research, 3(2): 121-137.

McQuilken, L.J. 2009. 'Justice-based service recovery in a service guarantee context', Unpublished doctoral dissertation, Deakin University Melbourne, Australia.

Megehee, C. 1994. 'Effects of experience and restitution in service failure recovery: Enhancing Knowledge Development in marketing'. In Achrol, R. \& Mitchell, A. (Eds.). Proceedings of the 1994 AMA Summer Educators conference. Chicago: IL: AMA, pp. 210-216.

Nunnally, J. C. \& Bernstein, I.H. 1994. Psychometric theory. New York: McGraw-Hill.

Priluck, R. \& Lala, V. 2009. 'The impact of the recovery paradox on retailer-customer relationships', Managing Service Quality: An International Journal, 19(1): 42-59.

Parkin, M. 2010. Micro-economics. $9^{\text {th }}$ Edition. Pearson Publishing.
Rust, R.T. \& Oliver, R.L. 2000. 'Should we delight the customer?' Journal of the Academy of Marketing Science, 28(1): 86-94.

Schoefer, K. \& Diamantopolous, A. 2008. 'The role of emotions in translating perceptions of (in)justice into postcomplaint behavioural responses', Journal of Service Research, 11(1): 91-103.

Shaw, L. 2008. 'Couple sue health department for R 13m'. The Herald Eastern Province (electronic edition), http://www.peherald.com/default. Accessed July 24, 2008.

Sheppard, B.H., Lewicki, R.J. \& Minton, J. 1992. Organisational justice. 1992. New York: Free Press.

Shore, T.H. 2004. 'Equity sensitivity theory: Do we all want what we deserve?', Journal of Managerial Psychology, 19(7): 722-728.

Sparks, B. A. \& McColl-Kennedy, J.R. 2001. 'Justice strategy options for increased customer satisfaction in a services recovery setting', Journal of Business Research, 54(3): 209-218.

Voss, G. B., Parasuraman, A. \& Grewal, D. 1998. 'The roles of price, performance, and expectations in determining satisfaction in service exchanges', Journal of Marketing, 62 (October): 46-61.

Webster, C. \& Sundaram, D.S. 1998. 'Service consumption criticality in failure recovery', Journal of Business Research, 41(2): 153-159.

Zeithaml, V.A., Bitner, M.J. and Gremler, D.D. 2006. Services Marketing: Intergrating Customer Focus across the Firm. 4th Edition. New York: McGraw-Hill.

Zikmund, W.G., Babin, B.J., Carr, J.C. \& Griffin, M. 2010. Business research methods. Cengage Publication. 


\section{APPENDIX A}

\section{EXAMPLES OF SCENARIOS}

\section{Scenario 1: Excessive compensation, excessive apologising}

You drop off a week's clothing at your neighbourhood dry-cleaner every Friday morning to be picked up the next day. On this occasion, when arriving at the dry cleaner on the Saturday afternoon you are informed by the manageress that there has been a misunderstanding and that your clothing will only be ready on Tuesday. The manageress then apologises for the misunderstanding. As the manageress escorts you to the front door she again apologises for the misunderstanding. During the course of the weekend and Monday the manageress phones you on three further occasions to apologise. On the Tuesday morning the clothing is ready as promised. When you pick up the clothing the manageress again apologises. "Because of the misunderstanding and the non-availability of your clothing on Friday I will not be charging you for the dry cleaning", she said. "It's on the house. I also want to offer you a discount voucher of 50\% off your next dry cleaning service at our firm".

\section{Scenario 8: High compensation, no apologising}

You drop off a week's clothing at your neighbourhood dry-cleaner every Friday morning to be picked up the next day. On this occasion, when arriving at the dry cleaner on the Saturday afternoon you are informed by the manageress that there has been a misunderstanding and that your clothing will only be ready on Tuesday. On the Tuesday morning the clothing is ready as promised. When you arrive at the dry cleaner to pick up the clothing the manageress says: "Because of the misunderstanding and the non-availability of your clothing on Friday I will not be charging you for the dry cleaning. It's on the house". 